\title{
Arduino-Based Controller for Sequence Development of Automated Manufacturing System
}

\author{
Shahad Sarmad Khaleel* Maher Yahya Salloom** \\ Ahmed M. Shammari*** \\ *, ***Department of Automated Manufacturing Engineering/ Al-Khwarizmi college of Engineering / \\ University of Baghdad \\ ** Department of Mechatronics Engineering/Al-Khwarizmi college/ of Engineering/University of Baghdad \\ *Email: shahadsarmad36@gmail.com \\ **Email: drmahir@kecbu.uobaghdad.edu.iq \\ ***Email: ahmadhzaam@yahoo.com
}

(Received 6 February 2020; accepted 5 July 2020)

https://doi.org/10.22153/kej.2020.07.001

\begin{abstract}
It has become necessary to change from a traditional system to an automated system in production processes, because it has high advantages. The most important of them is improving and increasing production. But there is still a need to improve and develop the work of these systems.

The objective of this work is to study time reduction by combining multiple sequences of operations into one process. To carry out this work, the pneumatic system is designed to decreasel increase the time of the sequence that performs a pick and place process through optimizing the sequences based on the obstacle dimensions. Three axes are represented using pneumatic cylinders that move according to the sequence used. The system is implemented and controlled to carry an object from one position to another. The movement of the system is controlled using three linear potentiometers, which are connected to an analog input of the microcontroller to feed the value of the pneumatic rod distance. To achieve the best path of the product moving, it is necessary to compare among several sequences. . The results show the sequences that compared with the reference under fixed speed, such as sequence that has been developed by combining two axes, and then the system path time has been reduced in taking the product from one place to another. Therefore, some factories need to reduce the sequences and thus reduce the time to transfer the product.
\end{abstract}

Keywords: Automation, pneumatic system, automated pick and place, sequence optimization.

\section{Introduction}

Factories need continuous improvement to keep pace with rapid development and maintain the success of the factory and its products; one of the most important sections that the final product depends on it is the handling machine. Different activities such as handling, sorting, moving can be done using handling machines where compressed air is suitable to do these jobs. The scale of factory success depends on the required time to complete product manufacturing. So, automated manufacturing has been used to reduce the time needed. Using material handling machines has a good impact on reducing the time to handle, transport, or separate products. Also, dropping down more than $80 \%$ of the time spent in waiting or transport of the material on the shop floor, which leads to reduce wastage, breakage, and loss of material [1].

In 2005, a novel altered heartbeat width regulation (MPWM) valve beating calculation introduced to permit on/off solenoid valves that can be utilized instead of expensive servo valves. A control execution correlation between the framework reaction of the standard PWM strategy and that of the altered PWM method demonstrated a critical presentation increment. A 
state-criticism controller with position, speed and quickening input was effectively actualized as a nonstop controller. An exchanging calculation for control boundaries utilizing a learning Vector Quantization Neural Network (LVQNN) has recently proposed, which arranges the outside heap of the pneumatic actuator. The adequacy of this proposed control calculation with smooth exchanging control has been exhibited through investigations with different outer loads [2].

One part of a mechanized framework. A gripper can be connected to a robot or it tends to be a piece of a fixed mechanization system, described guidelines for the design of grippers for use in modular manufacturing work cells. Guidelines have been applied to a wide variety of grippers [3].

Many tools contribute in development of automated manufacturing such in 2006, a novel single-camera vision framework to quantify part and board arrangement in Pick and Place machines. This framework is a piece of a creative idea for a quicker Pick and Place machine idea. A current two-camera vision framework is contrasted and the single-camera framework. Additionally, the mistake spending which impacts the last estimation precision is hypothetically examined for the novel single-camera vision framework [4]. In 2010, the structure of a computerized pick and spot framework was introduced. The fragmented parts are gathered from underneath. The segment ought to be gotten a handle on, raised it at the highest point of the stock, and moved into the weight machine. It needs to descend a little in the press machine to put the segment on the bite the dust shoe. Since these two tasks are comparable, the framework can be organized utilizing two arms situated symmetrical to one another. The main situation of the essential arm is meeting, the halfdone item, along these lines, it in a withdrawn position. The subsequent arm meets the weight machine, just as withdrawn. The two arms are hung on a third arm that returns vertically. The body of the three arms is put on a turning actuator. The framework can be planned for high adaptability as far as the quantity of different grippers that can be utilized. robotic/finger grippers can be utilized on non-attractive segments. This can be, practiced by utilizing pneumatic chambers of abbreviated stroke [5].

In 2013, built up an independent picking robot system for plantation developed tomatoes, which comprises of four significant parts: the end effectors, machine vision, robot bearer, and control system. Accomplished fruitful paces of coordinated picking. Thus, a self-governing picking robot system was effectively evolved and it should be additionally tried for genuine tomato picking tasks in plantations later on [6].

Pneumatic grippers are easy to utilize and are by and large financially savvy in light of the fact that pneumatic hardware's are anything but difficult to keep up. The handling of abstract materials and mechanisms to pick and place is widely found in factory automation and industrial manufacturing. In 2013, a two jaw drove gripper was planned that is not the same as the typical cam and sequent gripper through the controlled movement of the jaws which had done utilizing of pneumatic cylinders worked compressed air [7].

In 2015, the design and study of intelligent electric arc furnace applications system using a proportional directional control valve have been introduced. The tests showed that the electrohydraulic closed loop system for position was good and the output was good and acceptable [8].

In 2016, it has been structured and manufactured a pneumatic arm for pick and spot of round and hollow articles. The treatment of materials and instrument to pick and spot objects was from lower planes to higher planes. The planned pneumatic arm comprised of two chambers; a pole works with lead screw system fit for changing over movement of cylinder to rotational movement of arm with assistance of utilizing packed air. The planned procedures were completed dependent on coordinated data of kinematics elements and auxiliary investigation of the ideal robot arrangement. The profoundly powerful pneumatic arm model could be effortlessly set at middle of the road positions by controlling the weight utilizing the stream control valve. It could be utilized in stacking and emptying of products in a transportation harbor as the development of merchandise is done from lower plane to higher plane [9].

In 2016, pick- place system is an application that is extremely used in manufacturing. This pick -place activity is done all over the place and whenever in light of the fact that a great deal of human development includes picking and placing objects. Pick -place robot could be characterized as a basic robot. The fundamental capacity was to move things starting with one spot then onto the next. A strong gripper has been intended to perform simpler and quicker picking and putting tasks for different shapes and sizes objects [10]. 
The gripper improved the picking and setting activity in the assembling field to deliver more outputs without the requirements to reprogram every once to sense the object size. By the inciting vitality, gripper frameworks can be pneumatic, pressure driven, vacuum-based, servo-electric, attractive, and so forth. Determination of a specific sort of engine relies upon a large number of variables including the heaviness of the held onto object, the necessary speed for its grasping, the forced clipping power, the consistence of the whole framework, and so on. Pneumatic activation is one of the most every now and again experienced driving modalities of gripper frameworks, because of its points of interest. These incorporate the straightforwardness of the control graphs, the chance of securely overburdening the framework, simple support, the nondirtying working medium, consistence, and so forth. Another useful arrangement of a gripper framework impelled by a pneumatic muscle [11].

One of the major and most performed work is picking and putting of occupations from source to goal. These days, the business is progressively turning towards PC based robotization, chiefly because of the requirement for expanded efficiency and conveyance of final results with uniform quality. In 2017, pick and spot robot was intended to deal with an alternate shape and size and furthermore unpredictable items, the pick and spot robot can play out the pick and spot the sporadic parts on 260o inside the workspace [12].

In 2017, the plan and execution of pick and spot robot control framework on an equipment stage dependent on programmable rationale controllers (PLC) have been showed up, which interfaces with the detecting and incitation gadgets for robot control. The framework incorporates a pick and spot robot whereby a dream framework is coordinated with its workspace to distinguish work pieces concerning their shape and shading. Subsequent to detecting and perceiving the items highlights, MATLAB sends results to PLC. PLC sends related requests to the robot's joints, which are made of DC and stepper engines. The robot picks the item, finds it in its particular goal, and turns around to its reference area. The presentation of the created robot was confirmed through trial results [13].

The automatic production line can perform feeding, transportation, and sorting functions. In 2019, two SCADA/HMI systems were implemented using two different software. TIA portal software is used to build HMI, alarm, and trends in touch panel, which is helped an operator to control and monitor the production line. LabVIEW software is used to create HMI and patterns on the computer screen. It is linked with Microsoft Excel (ME) to generate an information table that helped to monitor the performance of the pneumatic equipment. The communication between master program TIA PORTAL V15 software and slave program LABVIEW is through OLE Process Control (OPC) service. OPC offers greater flexibility and lower cost of development, integration, and assembly for controlling and monitoring the industrial process. Moreover, the OPC can involve a wide variety of data resources, as in [14].

The most important of automated systems is that how to improve and increase production. But there is still need more efforts to improve and develop the work of these systems. The objective of this work is to study time reduction by combining multiple sequences of operations into one process.

In this work, a 3D-model of a pneumatic pick and place system is proposed. This approach uses several sequences of movements to get the best way of direction to pick an object from one position to another position with high accuracy.

\section{Basics of Control System}

The key constituents for any automatic process are: (1) power source, (2) input control component, and (3) programmable order structure, as appeared in figure.1.

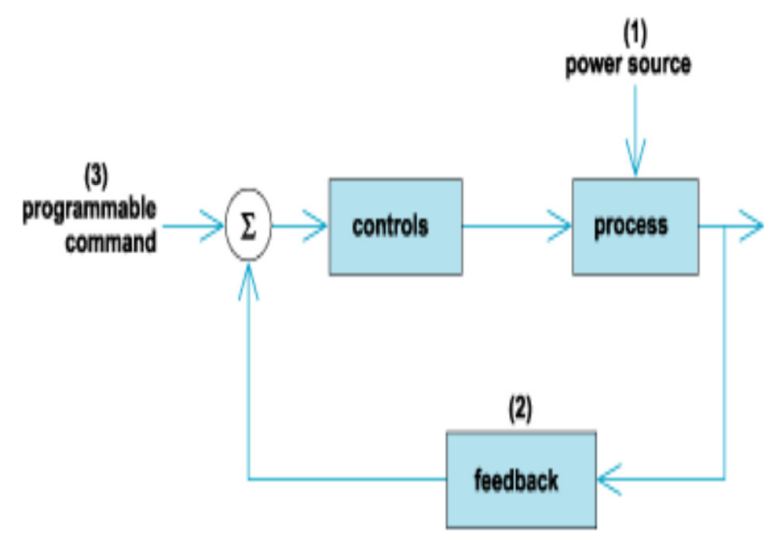

Fig.1. The fundamental constituents of any automated process [15]. 


\section{Control Loop of Proposed System}

The control loop for the system shown in figure 2 describes how the system works according to sensors. The controller gives feedback to the Arduino, which orders the directional control valve to take action by moving the cylinders.

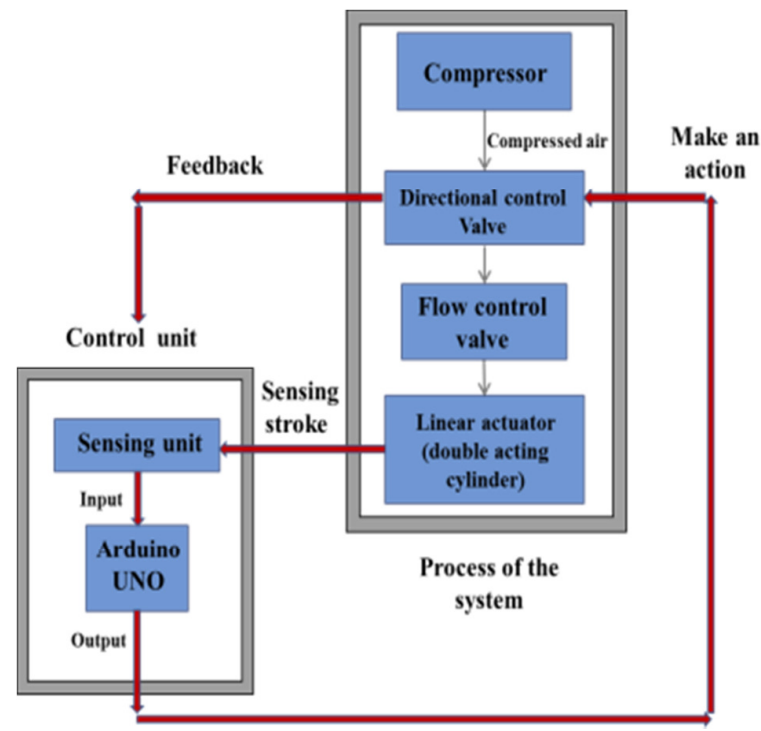

Fig. 2. The mechanism of work of the proposed system.

\section{Design of the Proposed System}

Initially, the mechanical part is designed by Solid Works program, as shown in figure 3 , where three axes $\mathrm{x}, \mathrm{y}$, and $\mathrm{z}$ are designed, as basis of their movement.

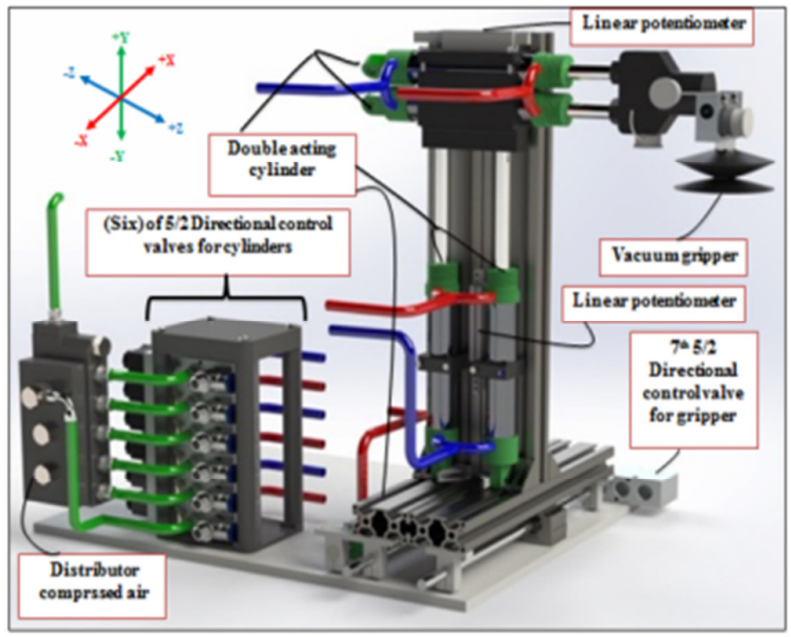

Fig. 3. 3D-module of the assembly parts.

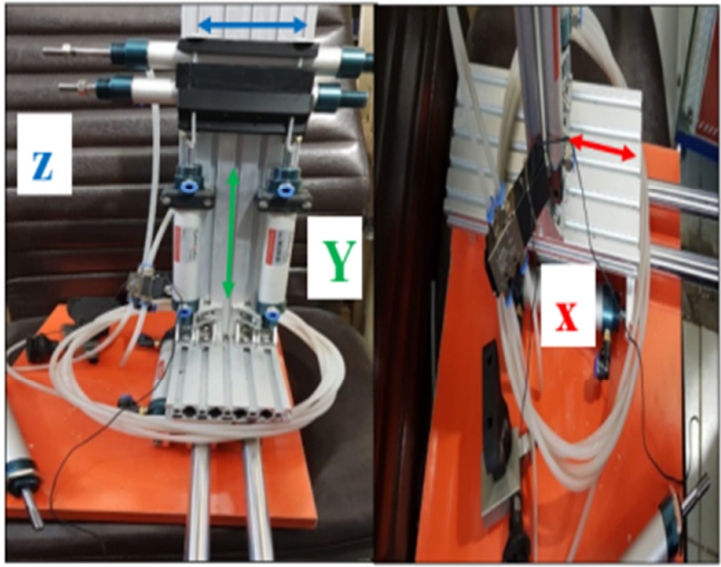

Fig.4: Layout of 3-axis pneumatic pick and place system.

After the mechanical part is designed through the Solid Works program, a motion simulation is created to verify the axes for design implementation. Five linear actuators, called pneumatic cylinder type double acting that makes up the system and layout in 3-axis, as shown in figures $(3 \& 4)$, one cylinder for the $x$-axis, two cylinders for the y-axis, and also two cylinders for the z-axis. Each cylinder requires two directional control valves type five-way/twoposition single solenoid return spring, one of which is responsible for extending and the other responsible for retracting. The $\mathrm{X}$-axis cylinder moves from one side to the other and vice versa and the $\mathrm{Y}$-axis cylinder moves up and down, and the $\mathrm{Z}$-axis cylinder whose movement is moving towards the piece and returns in the other direction. A vacuum gripper is installed at the end of the $\mathrm{Z}$-axis cylinder to grip and release the piece, which is its working principle Venturi pipe, as shown in figure 5

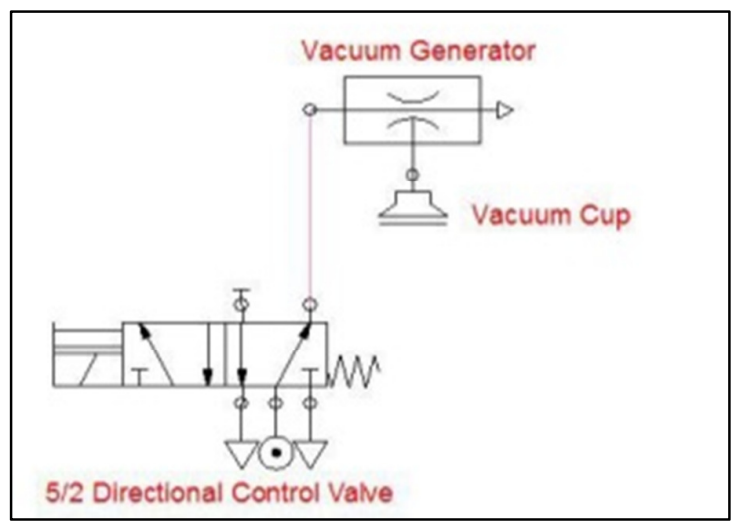

Fig. 5. Electro-pneumatic circuit of the vacuum gripper 
In order to be sensitive to the movement of these cylinders, it is necessary to add a sensor to the distance covered by the cylinder, this sensor called linear potentiometer. The final form of mechanical design, assembly, and air and electronic connection are shown in figure 6: $(a, b)$.

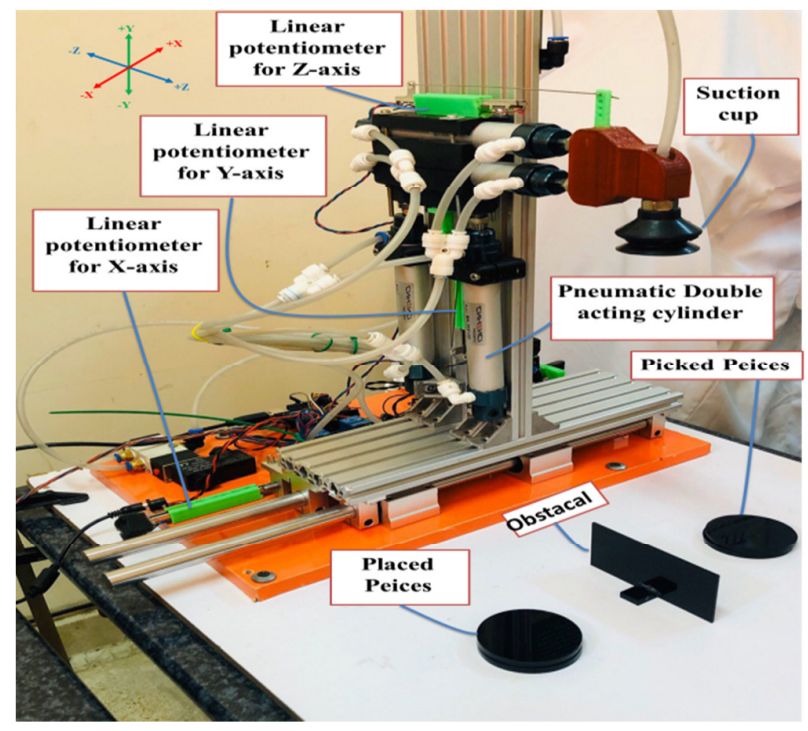

a

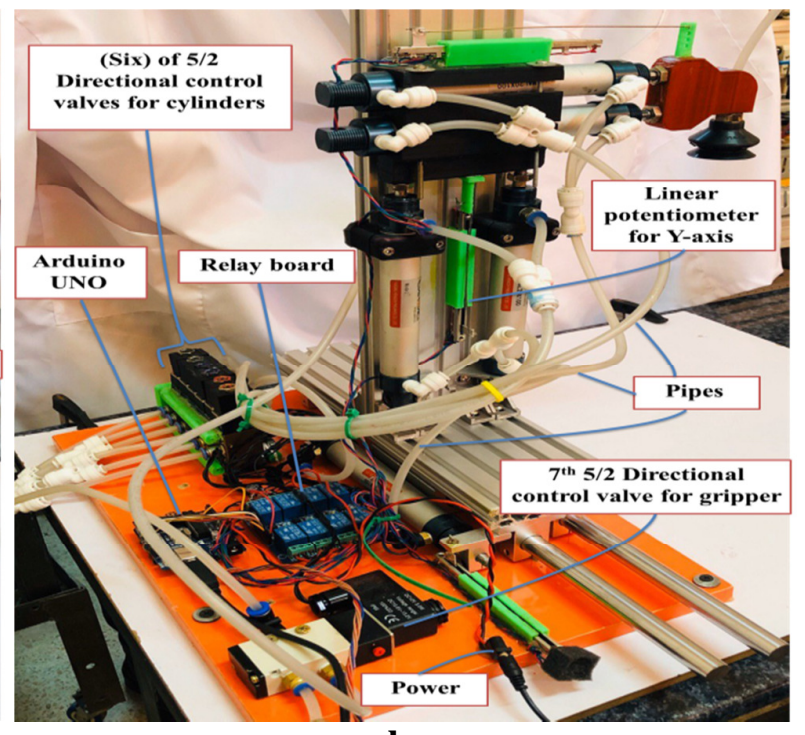

b

Fig. 6. a) Final mechanical design of pneumatic pick and place system, b) Components of the system.

All the measurements were taken by setting axis $(0,0,0)$ as the reference point and are set to be zero position. All directions are chosen to be positive with respect to the axis $(0,0,0)$. The fundamental Dimensions are tabulated in table1.

Table1,

The limitations of mechanical dimensions setup.

\begin{tabular}{ll}
\hline Parameter & Dimension in $\mathbf{~ m m}$ \\
\hline Max. X-axis & 100 \\
Max. Y-axis & 100 \\
Max. Z-axis & 100 \\
Min. X, Y, and Z-axes & 0 \\
Gripper diameter & 40 \\
Piece diameter & 50 \\
Cylinder outer diameter & 20 \\
Cylinder inner diameter & 10 \\
Stroke for all cylinders & 100 \\
\hline
\end{tabular}

\section{Controlling the System}

Microcontroller (Arduino UNO), gives an open-source and simple to using programming devices, for composing codes and transferring it to the board. It is regularly alluded to as the Arduino Integrated Development Environment (IDE). Arduino UNO is used for controlling the pneumatic system, through the entering signal from the linear potentiometer. It processes and directs to a current amplifier (relay board) to send a signal to the valves as an output signal, as shown in figure 7.

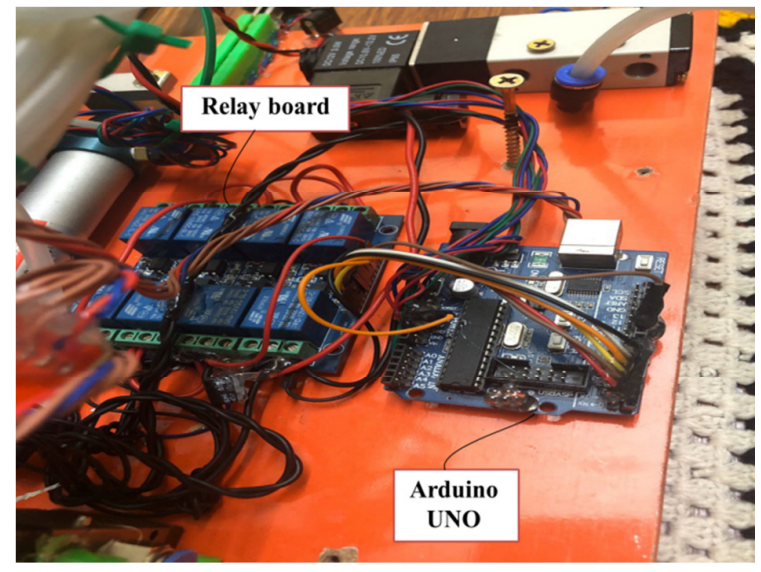

Fig. 7. Control Wiring.

Each valve needs a higher current as it works as a switch when the signal reaches it. As a result, the compressed air for the movement of the cylinder has controlled this responsibility, as illustrated in figure 8 . 


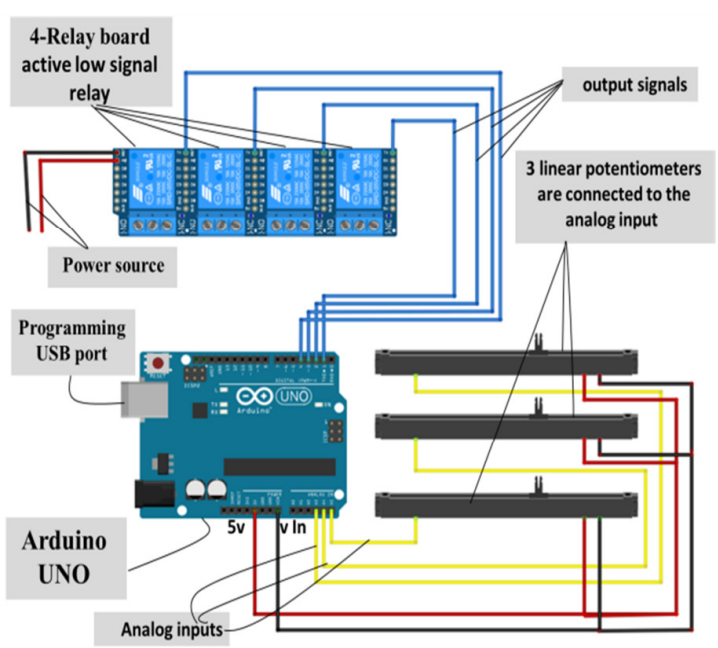

Fig. 8. Circuit of control system I/O.

Figure 9 shows the process of compressed air passed from the compressor into the system through plastic pipes to the directional control valves, and the out compressed air from the flow control valves into the system to make the desired movements for the pneumatic cylinders, as illustrated in figure 10.

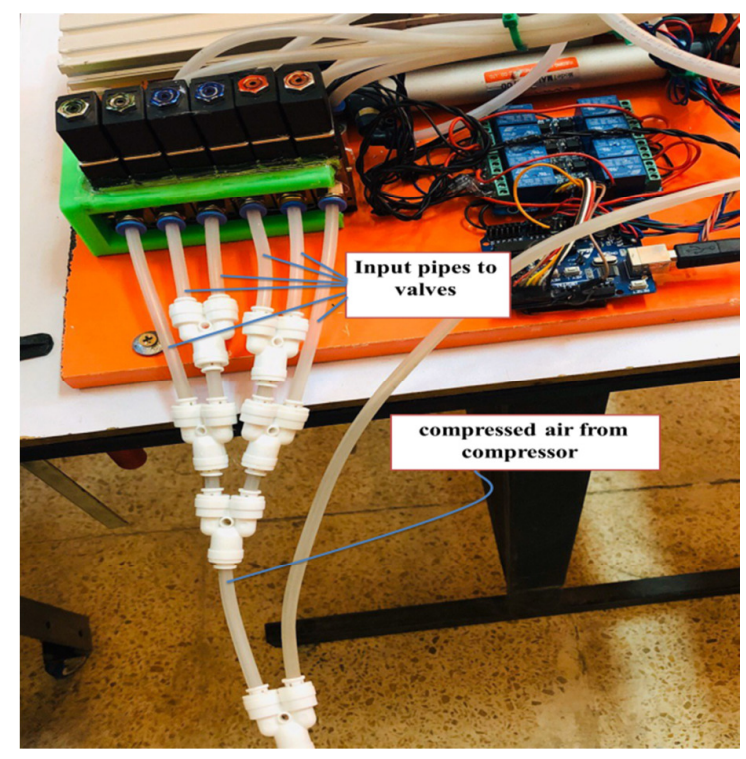

Fig. 9. Compressed air passing (Input compressed air) to the system.

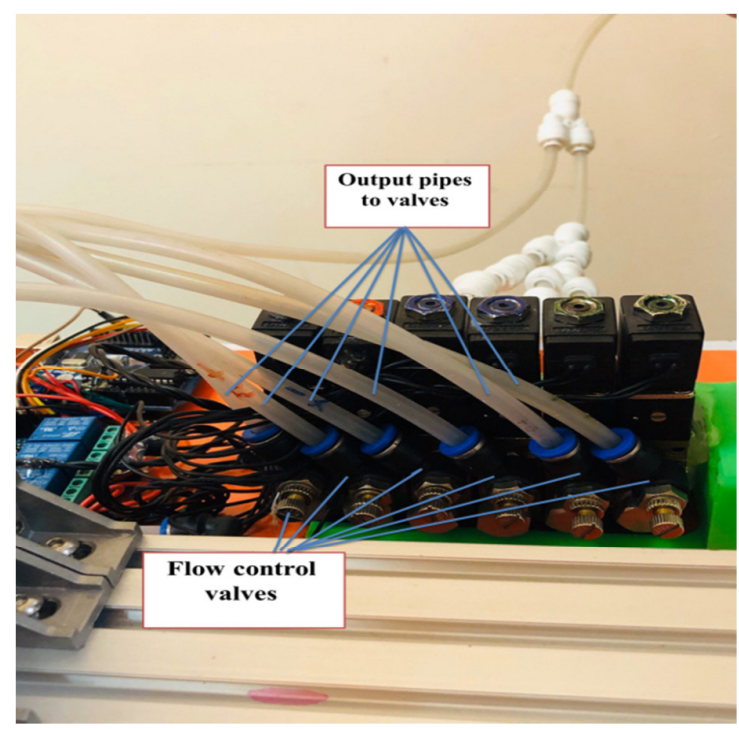

Fig.10: Compressed air passing (output compressed air) from flow control valve into the system.

This process is performed when the cylinder is run at every sequence. For the piece to be moved from one location to another should be implemented in several steps. Each step has time and coincides with the other step. Each axis is moved and synchronized according to the sequence that the system performs to cross the obstacle. Using programming Arduino should be insert the dimensions of the obstacle to be crossed. It stars from the top or from the side according to its lower dimensions to reduce the time of succession. It is choose the best and least time. As well the most accurate in position and the motion of cylinders will be in terms of the location of the piece and the smooth movement of the cylinders. This is done with several possibilities for three kind of obstacles.

These sequences can be programmed in Arduino in a specified algorithm as shown in figure11. 


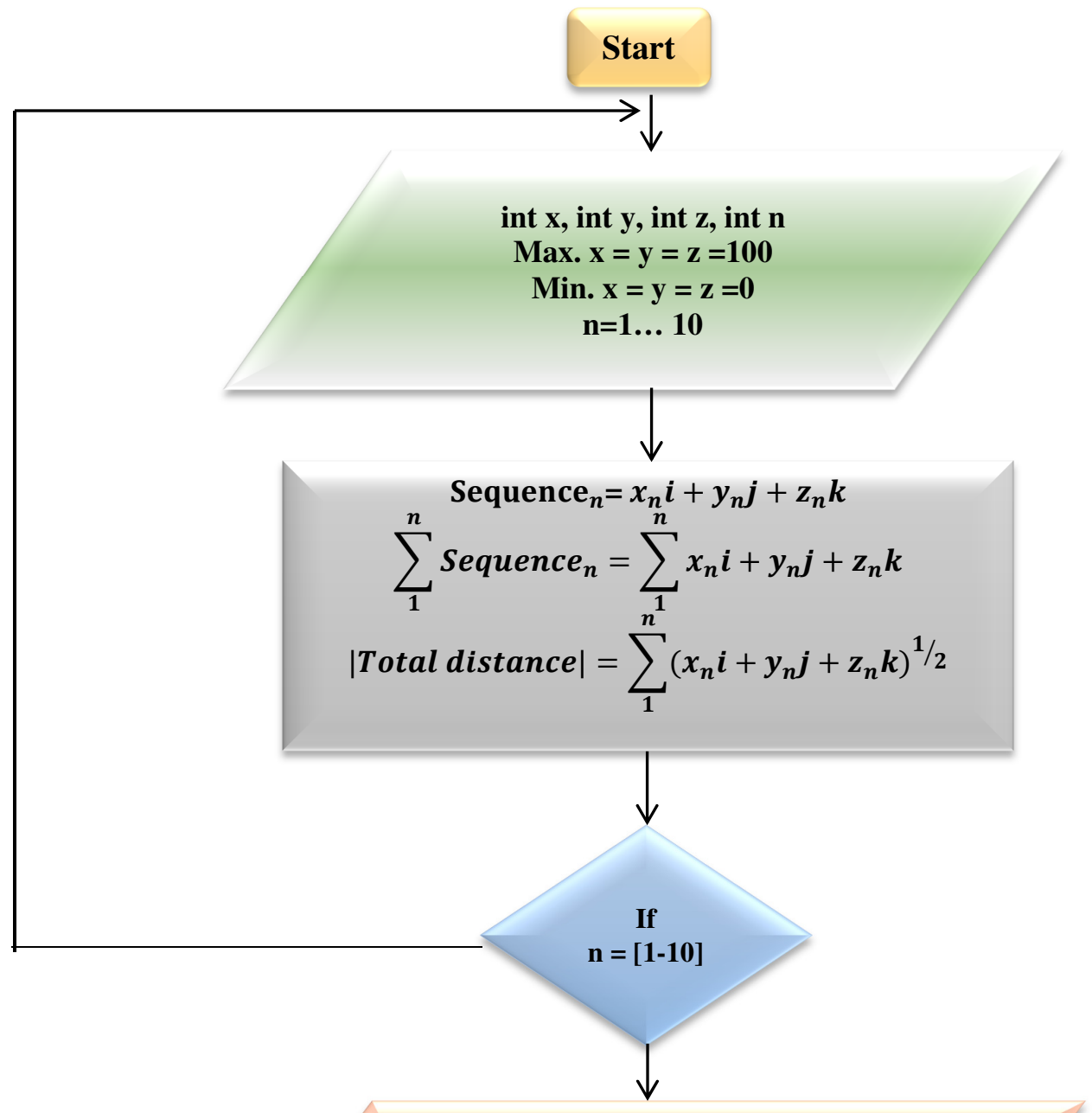

Write $\mid$ Total distance $\left.\right|_{1} ^{10}$

"Reference sequence of $1^{\text {st }}$ obstacle"

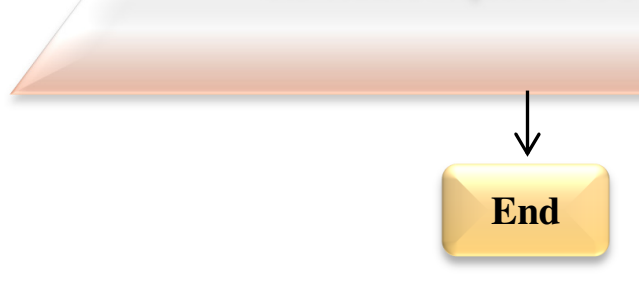

Fig.11. The flowchart of algorithm for Arduino program.

As the first barrier has a width greater than its height and the other the width is less than its height, then it exceeds the barrier from the lower side after the last and the last barrier is an equal dimensional barrier that exceeds diagonally, and have many cases of combining two or more axes which are three possibilities for each obstacle. These possibilities are: - XYZ (XY+YZ), XYZ (XZ+YZ), and YZ.
When these possibilities are implemented, they are considered several sequences in two cases, the first case represents the velocity of compressed airflow as a constant, while the second case considers the velocity as changed. Therefore; the time for each probability is calculated by writing a program in Arduino and outputting the time with the speed and with the distance and a comparison is made between them. A reference sequence is 
made for the first two obstacles and then it is improved by reducing its steps.

The following tables explain each sequence steps:

Table 2, explains the sequences of moving the piece from one place to another by operating each axis separately passing the first obstacle from its eight.

Table 2,

Reference sequence for the first obstacle.

\begin{tabular}{ccccc}
\hline Sequence & $\mathbf{X}$ & $\mathbf{Y}$ & $\mathbf{Z}$ & Comment \\
\hline $\mathbf{0}$ & 0 & 0 & 0 & Initial state \\
$\mathbf{1}$ & 0 & 1 & 0 & $\uparrow$ Y up \\
$\mathbf{2}$ & 0 & 1 & 1 & $\mathbf{Z}$ out \\
$\mathbf{3}$ & 0 & 0 & 1 & $\downarrow$ Y down \\
$\mathbf{4}$ & 0 & 1 & 1 & $\uparrow$ Y up \\
$\mathbf{5}$ & 1 & 1 & 1 & $\leftarrow$ X left \\
$\mathbf{6}$ & 1 & 0 & 1 & $\downarrow$ Y down \\
$\mathbf{7}$ & 1 & 1 & 1 & $\uparrow$ Y up \\
$\mathbf{8}$ & 0 & 1 & 1 & $\overrightarrow{\mathrm{X}}$ right \\
$\mathbf{9}$ & 0 & 1 & 0 & $\mathbf{Z}$ in \\
$\mathbf{1 0}$ & 0 & 0 & 0 & $\downarrow$ Y down \\
\hline
\end{tabular}

Improved and reduced sequence from 10 to 8 position steps in table3, by combining the movement of two axes together.

Table 3,

Enhanced on table 2 (YZ

\begin{tabular}{|c|c|c|c|c|}
\hline Sequence & $\mathbf{X}$ & $\mathbf{Y}$ & $\mathbf{Z}$ & Comment \\
\hline $\mathbf{0}$ & 0 & 0 & 0 & Initial state \\
\hline 1 & 0 & 1 & 0 & $\uparrow \mathrm{Y}$ up \\
\hline 2 & 0 & 0 & 1 & 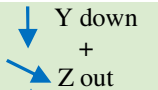 \\
\hline 3 & 0 & 1 & 1 & $\uparrow \mathrm{Y}$ up \\
\hline 4 & 1 & 1 & 1 & $\leftarrow X$ left \\
\hline 5 & 1 & 0 & 1 & $\downarrow \mathrm{Y}$ down \\
\hline 6 & 1 & 1 & 1 & $\uparrow Y$ up \\
\hline 7 & 0 & 1 & 1 & $\rightarrow \mathrm{X}$ right \\
\hline 8 & 0 & 0 & 0 & $\begin{array}{c}\mathrm{Y} \text { down } \\
+ \\
\mathrm{Z}_{\text {in }}\end{array}$ \\
\hline
\end{tabular}

Table 4, explains the sequences of moving the piece from one place to another by operating each axis separately passing the second obstacle from its width.
Table 4,

Reference sequence for the second obstacle.

\begin{tabular}{ccccc}
\hline Sequence & $\mathbf{X}$ & $\mathbf{Y}$ & $\mathbf{Z}$ & Comment \\
\hline $\mathbf{0}$ & 0 & 0 & 0 & Initial state \\
$\mathbf{1}$ & 0 & 1 & 0 & $\uparrow \mathrm{Y}$ up \\
$\mathbf{2}$ & 0 & 1 & 1 & $\searrow \mathrm{Z}$ out \\
$\mathbf{3}$ & 0 & 0 & 1 & $\downarrow \mathrm{Y}$ down \\
$\mathbf{4}$ & 0 & 0 & 0 & $\nwarrow \mathrm{Z}$ in \\
$\mathbf{5}$ & 1 & 0 & 0 & $\leftarrow \mathrm{X}$ left \\
$\mathbf{6}$ & 1 & 0 & 1 & $\searrow \mathrm{Z}$ out \\
$\mathbf{7}$ & 1 & 0 & 0 & $\nwarrow \mathrm{Z}$ in \\
$\mathbf{8}$ & 0 & 0 & 0 & $\rightarrow \mathrm{X}$ right \\
\hline
\end{tabular}

Table 5,

Enhanced on table 4 (YZ)

\begin{tabular}{|c|c|c|c|c|}
\hline Sequence & $\mathbf{X}$ & $\mathbf{Y}$ & $\mathbf{Z}$ & Comment \\
\hline $\mathbf{0}$ & 0 & 0 & 0 & Initial state \\
\hline 1 & 0 & 1 & 0 & $\uparrow \mathrm{Y} \mathrm{up}$ \\
\hline 2 & 0 & 0 & 1 & 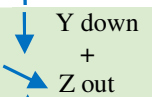 \\
\hline 3 & 0 & 1 & 0 & $\begin{array}{c}\mathrm{Y} \begin{array}{c}\mathrm{Y} \text { up } \\
+ \\
\mathrm{Z} \\
\mathrm{Z} \text { in }\end{array}\end{array}$ \\
\hline 4 & 1 & 1 & 0 & $\rightarrow \mathrm{X}$ left \\
\hline 5 & 1 & 0 & 1 & 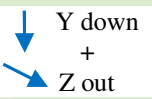 \\
\hline 6 & 1 & 0 & 0 & $\mathrm{Z}$ in \\
\hline 7 & 0 & 0 & 0 & $\rightarrow X$ right \\
\hline
\end{tabular}

In Tables 6, 7, and 8 the sequences reduced by merged tow axes in different planes $\mathrm{YZ}$ plane, $\mathrm{YX}$ plane and $\mathrm{XZ}$ plane to be enhancement for early mentioned tables.

Table 6,

Enhanced on table 2, XYZ (XY+YZ).

\begin{tabular}{|c|c|c|c|c|}
\hline Sequence & $\mathbf{X}$ & $\mathbf{Y}$ & $\mathbf{Z}$ & Comment \\
\hline $\mathbf{0}$ & 0 & 0 & 0 & Initial state \\
\hline 1 & 0 & 1 & 1 & $\begin{array}{c}\uparrow \mathrm{Y}_{\text {up }} \\
+ \\
\mathrm{Z} \text { out }\end{array}$ \\
\hline 2 & 0 & 0 & 1 & $\downarrow \mathrm{Y}$ down \\
\hline 3 & 1 & 1 & 1 & $\begin{array}{c}\leftarrow \text { X left } \\
+ \\
\uparrow \quad \mathrm{Y} \text { up }\end{array}$ \\
\hline 4 & 1 & 0 & 1 & $\begin{array}{c}\leftarrow \quad X \text { left } \\
\downarrow+ \\
\downarrow \quad \text { down }\end{array}$ \\
\hline 5 & 0 & 1 & 1 & $\begin{array}{c}\rightarrow \mathrm{X} \text { right } \\
\hat{\mathrm{T}}+ \\
\mathrm{Y} \text { up }\end{array}$ \\
\hline 6 & 0 & 0 & 0 & $\begin{array}{l}\rightarrow \quad \mathrm{X} \text { right } \\
+\stackrel{+}{\downarrow} \mathrm{Y}_{\text {down }} \\
+ \\
\mathrm{Z}_{\text {in }}\end{array}$ \\
\hline
\end{tabular}


Table 7,

Enhanced on table 4, XYZ (XZ+YZ).

\begin{tabular}{|c|c|c|c|c|}
\hline Sequence & $\mathbf{X}$ & $\mathbf{Y}$ & $\mathbf{Z}$ & Comment \\
\hline $\mathbf{0}$ & 0 & 0 & 0 & Initial state \\
\hline 1 & 0 & 1 & 1 & $\begin{array}{c}\text { † Y up } \\
+ \\
\mathrm{Z}_{\text {out }}\end{array}$ \\
\hline 2 & 0 & 0 & 1 & $\downarrow \mathrm{Y}$ down \\
\hline 3 & 1 & 0 & 0 & $\begin{array}{c}-X \text { left } \\
+ \\
Z_{\text {in }}\end{array}$ \\
\hline 4 & 1 & 0 & 1 & $\begin{array}{c}X_{\text {left }}^{+} \\
\mathrm{Z}_{\text {out }}^{+}\end{array}$ \\
\hline 5 & 0 & 0 & 0 & $\begin{array}{c}\rightarrow \quad \mathrm{X} \text { left } \\
+ \\
\mathrm{Z}_{\text {in }}\end{array}$ \\
\hline
\end{tabular}

For third obstacle which is equilateral the process to passed this obstacle performed in 6 sequences as in Table8

Table 8,

Enhanced sequence for the third obstacle.

\begin{tabular}{|c|c|c|c|c|}
\hline Sequence & $\mathbf{X}$ & $\mathbf{Y}$ & $\mathbf{Z}$ & Comment \\
\hline $\mathbf{0}$ & 0 & 0 & 0 & Initial state \\
\hline 1 & 0 & 1 & 1 & 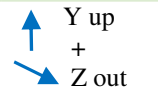 \\
\hline 2 & 0 & 0 & 1 & $\downarrow Y$ down \\
\hline 3 & 1 & 1 & 0 & $\begin{array}{c}\leftarrow \text { X left } \\
+ \\
+ \\
Y^{+} \text {up } \\
+ \\
\mathrm{Z}_{\text {in }}\end{array}$ \\
\hline 4 & 1 & 0 & 1 & $\begin{array}{c}\leftarrow \quad \mathrm{X} \text { left } \\
+\stackrel{+}{+} \\
\downarrow \mathrm{Y}_{\text {down }} \\
+ \\
\mathrm{Z}_{\text {out }}\end{array}$ \\
\hline 5 & 0 & 1 & 0 & $\begin{array}{c}\rightarrow \text { X right } \\
+ \\
+ \\
\mathrm{Y}_{\text {up }} \\
+ \\
+ \\
\mathrm{Z}_{\text {in }}\end{array}$ \\
\hline 6 & 0 & 0 & 0 & $\begin{array}{l}\rightarrow \begin{array}{l}\mathrm{X} \text { right } \\
+ \\
{ }^{+} \mathrm{Y} \text { down }\end{array}\end{array}$ \\
\hline
\end{tabular}

When executing the above processes tables, the time of each process is calculated and an indication of whether it can be performed in both the fixed and variable speed cases.

\section{Results and Discussion}

Different values are given in time and distance to get the optimum path that the system can take. The curve in figure 12 shows that the time required completing the job that was the most extended way to pick an object and place it in the desired position.

Curve in figures 13 shows the proposed system need less time with less distance compared to previous, where enhanced preform on YZ axes.

The curve in figure 14 shows the enhanced in $\mathrm{YZ}$ and $\mathrm{XY}$ axes lead to less time when compared with sequences that only improve in the YZ axes, but the system moves in the same distance.

All the above enhanced were preform for the first obstacle that refers to Table 2. Sometimes the enhancement can be done on several axes and sometimes the improvement can occur only on two axes.

Now for the second obstacle that refers to Table 4, the time and distance less than in the first obstacle which can get by enhancement in sequences as the curve shown in figure 15 .

The curve in figure 16 shows that the enhanced YZ axes perform less time with long-distance compared to the reference, and less time with long-distance when compared with enhanced YZ axes in the first obstacle.

The curve in figure 17 shows the enhanced $\mathrm{YZ}$ and $\mathrm{XZ}$ axes for the second obstacle gives less time with long-distance when is compared with the origin and less time with long-distance when is compared with YZ-XZ for the first obstacle.

These differences in values are normal as cannot get less time with a short distance. Another consideration parameter such as smooth movements is also important, because any high speed or high pressure may cause a vibration in the system that led to a decreased accuracy. Several ways can be used to get the desired results. One of them is the traditional way where only one cylinder moves in each sequence, and the other way is many cylinders move in the same level, such as x-axes with $y$-axes, $x$ with $z$, y with $z$, or all axes move with each other in the same sequence.

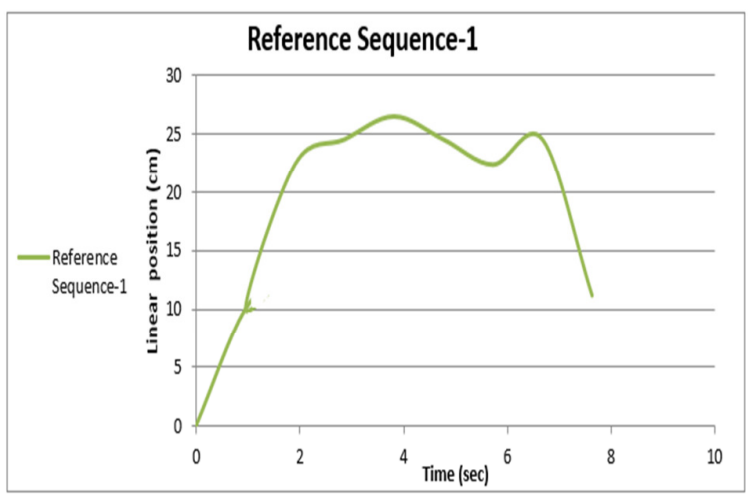

Fig. 12. Reference sequence for the first obstacle. 


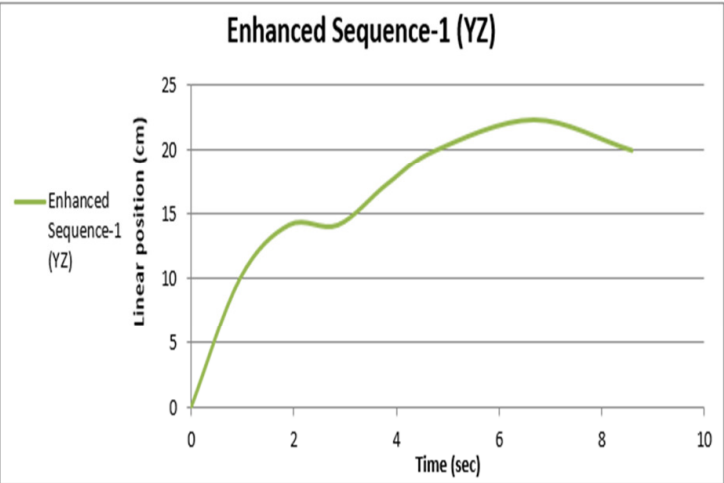

Fig. 13. Enhanced sequence (YZ) for the first obstacle.

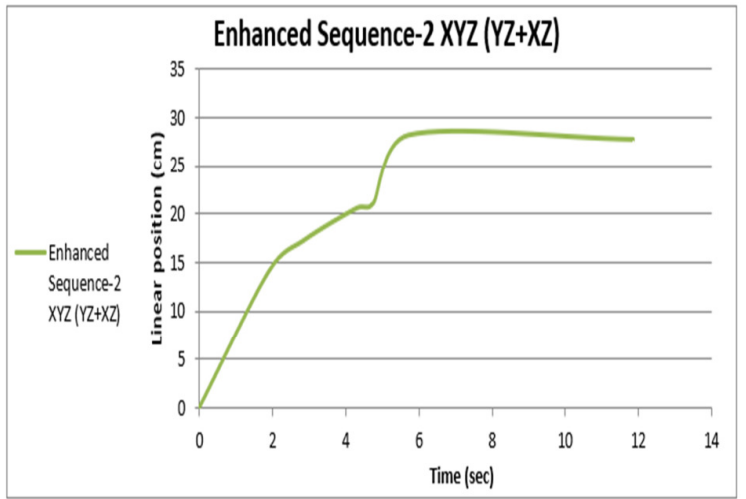

Fig. 14. Enhanced sequence $X Y Z(Y Z+X Y)$ for the first obstacle.

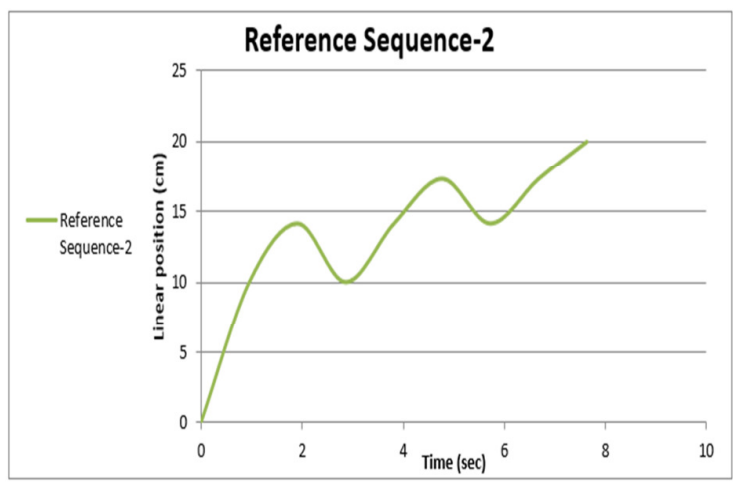

Fig. 15. Reference sequence for the second obstacle.

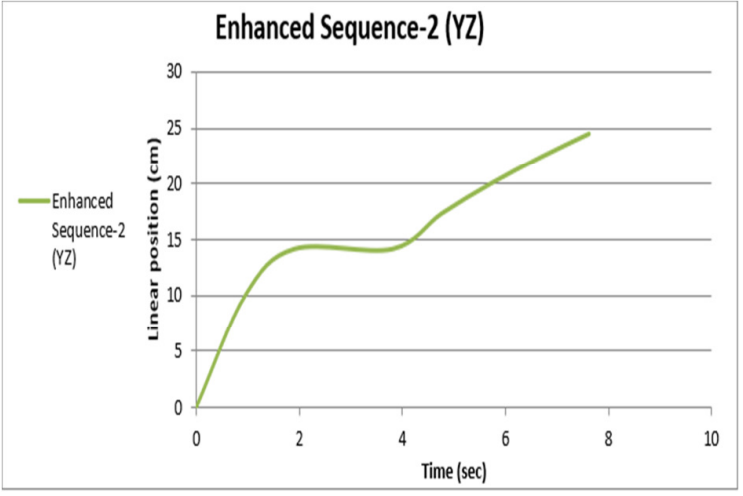

Fig. 16. Enhanced sequence (YZ) for the second obstacle.

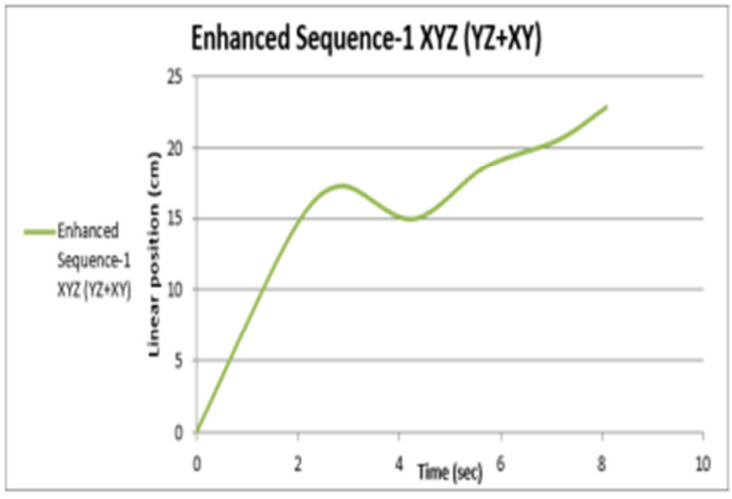

Fig.17. Enhanced sequence $X Y Z(Y Z+X Z)$ for the second obstacle.

\section{Conclusion}

A pick-place system was developed with pneumatic linear double-acting cylinders to applicator in automated systems processes for manufacturing. The most important of automated systems is to improving and increasing production, where the reduction of sequences time of the processes contributes to increasing production. The 3-axes movement was achieved. Arduino controls with these axes, through merged between two or three axes according to the selected sequence in the program, Sometimes the enhancement can be done on several axes, and sometimes the improvement can occur only on two axes. Another consideration parameter such as smooth movements is also important, because any high speed or high pressure may cause a vibration in the system that led to a decreased accuracy. These differences in values are normal as they cannot get less time with a short distance, several ways can be used to get the desired results. 


\section{References}

[1] A. Jahid, S. Mustakim, S. Sahil, S. Shaibaz, and V. D. Londhe, "Six axis pneumatic materials handling robotic arm," International Research Journal of Engineering and Technology (IRJET) vol.5,no.3,pp. 3955-3959, 2018.

[2] K. Ahn,"Intelligent switching control of pneumatic actuator using on / off solenoid valves," Mechatronics Elsevier Ltd, vol.15 no.6, pp. 683-702, 2005.

[3] T. Mravlje, "Guidelines for the design of robotic gripping systems," Ljubljana: University of Ljubljana, pp. 1-24, 2005.

[4] P. Verstegen, S. van Gastel, and J.W. Spronck, "Design of a novel single camera vision system for both component and board alignment in pick and place machines," IFAC Proceedings Volumes (IFAC-Papers Online), vol.4 pp. 706-712, 2006.

[5] O. Sastr, S. Hampapur, "Automated pick and place system 1," International Conference on Mechanical and Electrical Technology (ICMET), pp. 682-686, 2010.

[6] Y. Chui, S. Chen, and J. Lin, "Study of an autonomous fruit picking robot system in greenhouses," Engineering in agiriculture, environment and food, vol.6, no.3, pp. 92-98, 2013.

[7] K. Mohammed, T. Prasad, and, R. Mohammed,"Design \& analysis of a two-jaw parallel pneumatic gripper abstract," International Journal Of Computational Engineering Research (ijceronline.com), vol.3,no.12, pp. 41-46, 2013.

[8] M. Sallom, "Stabilizing Gap of Pole Electric Arc Furnace Using Smart Hydraulic System," Al-Khwarizmi Engineering Journal, vol.11, no.1, p.p.11-18, 2015.

[9] C. Santosh, C.Manoj, A. Peddarajula, and et al, "Design and fabrication of pneumatic arm for pick and place of cylindrical objects," International Journal of Latest Technology in Engineering, Management \& Applied Science (IJLTEMAS), vol.4, no.5, pp. 111116, 2016.

[10] S.Dinde, S. Kawale, Y. Parkhe, and et al, "Pneumatic arm control using microcontroller," International Journal of Advanced Research in Computer Science and Software Engineering, vol.6,no.4,pp. 681683, 2016.
[11] T. Deaconescu, A. Deaconescu, "Pneumatic muscle actuated compliant gripper system," RICEME-17, pp. 1-5, 2017.

[12] V. Sathishkumar, R. Rathish, "Four-Axis Material Handling Robot using Mechanical Gripper," International Journal of Engineering Research \& Technology (IJERT), vol.5, no.14, pp. 1-4, 2017.

[13] S. Kazemi, H. Kharrati, "Visual processing and classification of items on moving conveyor with pick and place robot using PLC", Intelligent industrial systems, vol.3, no.1, pp. 15-21, 2017.

[14] H. Hadi, M. Salloom, "pneumatic control system of automatic production line using SCADA implement PLC," Al-Khwarizmi Engineering Journal, vol.15, no.3, pp. 16-28, 2019.

[15] R. Praveen, T. Nirmalraja, H. Goutham, and et al,"Industrial Automation System," Advance in Electronic and Electric Engineerin,vol.3, no.6, pp. 717-726, 2013. 


\title{
ايجاد افضل وقت لتسلسل احدى عمليات الانتاج التي تعمل بقرة الموائع

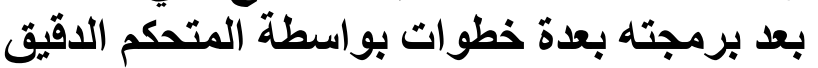

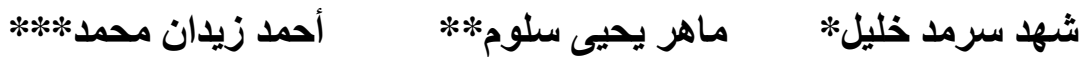

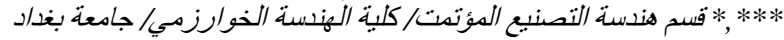

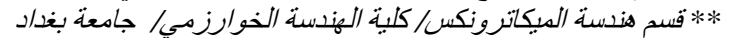 \\ * البريد الالكتروني: و \\ alabasy2001@yahoo.com * البريد الألكتروني: \\ ahmadhzaam@yahoo.com البريد الألكتروني:
}

الخلاصة

لقد أصبح من الضروري التغيير من نظام تقليدي إلى نظام آلي في عمليات الإنتاج لأنه يتمتع بمز ايا عالية. أهمها تحسين وزيادة الإنتاج. ولكن لا نز ال هناك حاجة لتحسين ونطوير الفروب عمل هذه الأنظمة.

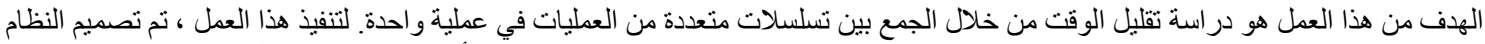

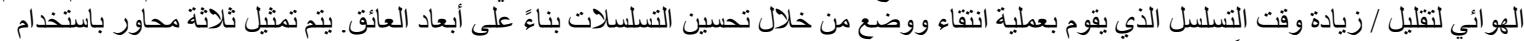

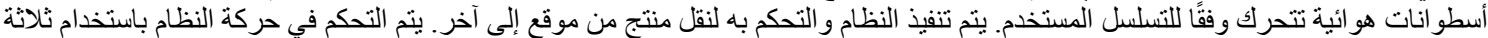

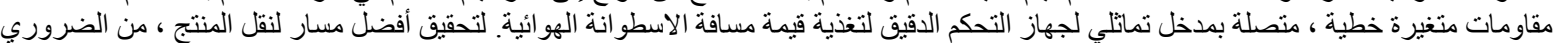

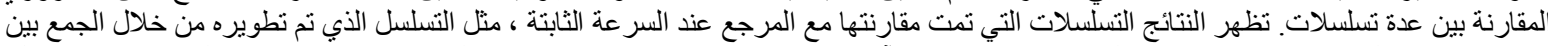

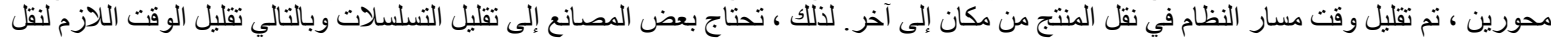

